\title{
EFFECT OF HEAT TREATMENT ON THE SURFACE COLOR OF RUBBER WOOD (HEVEA BRASILIENSIS)
}

\author{
Huichuan Jiang, Quanji Lu, Guanjun Li, Min Li, Jianing Li \\ Rubber Research Institute \\ Chinese Academy of Tropical Agricultural Sciences \\ CHINA
}

(Received October 20i9)

\begin{abstract}
In this study the effect heat treatment process parameters (temperature, duration and heating rate) on the surface color of rubber wood was evaluated. The color of the rubber wood was determined using CIE $L^{*} a^{*} b^{*}$ system before and after the heat treatment. The colorimetric properties, including total color difference $\left(\Delta E^{*}\right)$, lightness index $\left(L^{*}\right)$, red-green index $\left(a^{*}\right)$, and yellow-blue index $\left(b^{*}\right)$, were investigated at different treatment conditions. The results of analysis of variance (ANOVA) indicate that the heat treatment temperature has a significant effect on the colorimetric properties of the heat-treated rubber wood, duration and heating rate has no effect. Within the experimental range, as the heat treatment temperature and duration increasing, the color of the rubber wood gradually deepens. In order to achieve a surface color like the teak wood, the optimum process conditions are heat treatment temperature $190^{\circ} \mathrm{C}$, duration $4 \mathrm{~h}$, heating rate $10^{\circ} \mathrm{C} \cdot \mathrm{h}^{-1}$.
\end{abstract}

KEYWORDS: Heat treatment, rubber wood, process parameters, surface color, Hevea brasiliensis.

\section{INTRODUCTION}

Hevea brasiliensis, the para rubber tree, is a tree belonging to the family Euphorbiaceae. The rubber tree is native to Brazil and introduced to China in 1904. It is one of the important economic crops in the tropics of China which mainly planted in Hainan, Yunnan, Guangdong province for production of latex. Rubber trees are generally cut down after 25 - 30 years, because latex production declines as trees age, and they are no longer economically productive. Felled rubber trees have become the main plantation commercial timber in the tropical region of China, which were either burned on the spot or used as fuel before its commercialization in the past. Rubber wood is a by-product of the natural rubber industry which can bring more income to rubber planter in the face of a still-weak natural rubber economy. 
Rubber wood is now one of the major resources for making furniture with its favorable qualities and light color. As an important feature of wood related to the wood species identification, utilization and modification (Kúdela et al. 2018, Shi et al. 2018), the wood color is an essential aspect that affects the overall appearance of wood products such as furniture, floors, art and decorative materials (Jankowska and Stepniewski 2010). Heat treatment of wood at high temperatures from $150^{\circ} \mathrm{C}$ to $260^{\circ} \mathrm{C}$ is an environment-friendly method of improving dimensional stability, durability and changing the color of wood (Lin et al. 2017). Wood darkens on heat treatment with the color homogeneous throughout (Srinivas and Pandey 2012). With a light- to dark-brown appearance, heat-treated wood can be a substitute for some of the endangered tropical hardwoods such as teak wood. Heat treatment produced a wide range of color changes in the wood that might make the material more appealing to architects and designers (Yan and Morrell 2019). Most studies have suggested that the color change of heat treatment wood is highly dependent upon the wood species (Varga and Van der Zee 2008) and previous studies have also attempted analyzed the effect of treatment temperature or time on color changes (González-Peña and Hale 2009, Wongprot et al. 2013, Dzurenda 2018, Hrčková et al. 2018, Sikora et al. 2018, Cai et al. 2019, Esteves et al. 2019, Gašparík et al. 2019).

Sikora et al. (2018) studied the effect of the thermal modification temperature on color changes of spruce and oak wood and found that wood surface lightness $\left(L^{*}\right)$ decreased with increasing of treatment temperature and the highest color difference $\left(\Delta E^{*}\right)$ at $210^{\circ} \mathrm{C}$ was achieved. Salca et al. (2016) studied the color changes in black alder and beech wood veneers subjected to heat treatment at $190^{\circ} \mathrm{C}$ for different time spans. They found that the progress of discoloration depended on each wood species. The changes in color were caused mostly by the reduction in lightness. Heat treatment could enhance the use of such wood species for value added products in furniture manufacturing as an alternative to expensive tropical species. Some researchers analyzed the color responses of untreated and thermally modified Eucalyptus grandis samples at three different temperatures of thermal modification by the Brazilian industrial process VAP HolzSysteme ${ }^{\circledR}$ (Griebeler et al. 2018a). They also found a new method that consists of combining wood pre-grading by surface color followed by the application of homogeneity thermal treatments to reduce the surface color variability of the thermally modified blue gum wood (Griebeler et al. 2018b).

Nasir et al. (2019) studied the effect of thermal modification on the color of western hemlock wood. They focused on the prediction of material properties of thermally modified wood based on the color change via the "group method of data handling (GMDH)" neural network (NN). They suggested that color parameters combined with the GMDH-type NN successfully predicted the physical properties of the material and the color parameters showed a significant correlation with temperature and are well correlated with the heat treatment intensity. Van Nguyen et al. (2018) studied the relationship between the process parameters of heat treatment and the color change of wood using an artificial neural network (ANN). They found that ANN models can be used successfully for predicting the color changes in wood during heat treatment without the need of conducting experimental studies that are expensive and time consuming. However, there is a lot of work related to other wood species to be done for the only two wood species adopted in the study.

Zhao et al. (2019) studied the influences of thermal treatment on mechanical properties and surface characteristic of rubber wood and tried to find the mathematical model to predict the mechanical properties used by its surface characteristic. It was found that chromaticity parameters $b^{*}, \Delta E^{*}$ could evaluate the mechanical properties of thermally modified wood to achieve the mechanical properties detection without destruction. 
However, there is not enough published studies about heat-treated rubber wood, especially on the relationship of color change and treatment process parameters taking teak wood as a reference. This paper reports the effect of heat treatment process parameters (heat treatment temperature, duration and heating rate) on the surface color of heat-treated rubber wood with a view to its use for interior application such as solid wood flooring and furniture. The study derives an optimum process condition for the heat-treatment of rubber wood in order to get a color like the teak wood according to consumers' preferences, without the application of any varnishes or stains on the rubber wood surface.

\section{MATERIAL AND METHODS}

\section{Materials}

Rubber wood from 10 years old rubber trees (Hevea brasiliensis) from experimental farm of Chinese Academy of Tropical Agricultural Sciences (Danzhou city, Hainan province, China). Samples with the dimensions $150 \mathrm{~mm}$ (longitudinal) $\times 50 \mathrm{~mm}$ (tangential) $\times 10 \mathrm{~mm}$ (radial) were prepared. All the samples were air dried for more than three months. The average density and moisture content of samples was $600 \mathrm{~kg} \cdot \mathrm{m}^{-3}$ and $12 \pm 2 \%$, respectively.

\section{Methods}

\section{Wood heat treatment}

The heat treatment was performed according to the ThermoWood ${ }^{\circledR}$ method, using a $0.3 \mathrm{~m}^{3}$ thermal chamber (Jiangsu XINAN Wooddrying Systems Co., LTD, Nanjing, China). The treatment started at an initial temperature of $60^{\circ} \mathrm{C}$ and up to $130^{\circ} \mathrm{C}$ by a step of $10^{\circ} \mathrm{C} \cdot \mathrm{h}^{-1}$. And the temperature was increased at different heating rate up to the desired final temperature lasting different duration according to the test design in Tab. 1. After heat treatment, the wood was slowly cooled until reaching $40^{\circ} \mathrm{C}$.

Tab. 1: Design for orthogonal test $L_{9}\left(3^{4}\right)$.

\begin{tabular}{|c|c|c|c|}
\hline No. & Temperature $\left({ }^{\circ} \mathrm{C}\right)$ & Duration $(\mathrm{h})$ & Heating rate $\left({ }^{\circ} \mathrm{C} \cdot \mathrm{h}^{-1}\right)$ \\
\hline 1 & 170 & 2 & 10 \\
\hline 2 & 170 & 3 & 15 \\
\hline 3 & 170 & 4 & 20 \\
\hline 4 & 190 & 2 & 15 \\
\hline 5 & 190 & 3 & 20 \\
\hline 6 & 190 & 4 & 10 \\
\hline 7 & 210 & 2 & 20 \\
\hline 8 & 210 & 3 & 10 \\
\hline 9 & 210 & 4 & 15 \\
\hline
\end{tabular}

\section{Colorimetric properties measurement}

Color changes were characterized using the Commission Internationale de L'Eclairage $L^{*} a^{*} b^{*}$ (CIE $L^{*} a^{*} b^{*}$ ) color space (Jiang and Fu 2017). A X-Rite Ci60 portable spectrophotometer (X-Rite Pantone, Michigan, United States) was used for the color measurement. A D65 light source and 10 degree observed angle were used with an $8 \mathrm{~mm}$ diameter sensor head. The colorimetric properties at the points (1) to (6) (Fig. 1) were measured on both sides of each specimen and 
calculated mean value. The test points were selected with uniform color, not evenly distributed on both sides. The points were retained unchanged before and after the heat treatment. The CIE $L^{*} a^{*} b^{*}$ color system measures lightness $\left(L^{*}\right)$ of the sample, red-green index $\left(a^{*}\right)$ and yellow-blue index $\left(b^{*}\right)$. The total color difference $\left(\Delta E^{*}\right)$ was calculated based on the components:

$$
\Delta E^{*}=\left[\left(\Delta L^{*}\right)^{2}+\left(\Delta a^{*}\right)^{2}+\left(\Delta b^{*}\right)^{2}\right]^{1 / 2}=\left[\left(L^{*}-L_{T 0}{ }^{*}\right)^{2}+\left(a^{*}-a_{T 0}{ }^{*}\right)^{2}+\left(b^{*}-b_{T 0}{ }^{*}\right)^{2}\right]^{1 / 2}
$$

Where: $\Delta L^{*}$ is lightness difference $(-), \Delta a^{*}$ is red-green difference $(-), \Delta b^{*}$ is yellow-blue difference ( -$), L_{T 0}{ }^{*}$ is lightness values of the untreated teak wood $(-), a_{T 0}{ }^{*}$ is red-green values of the untreated teak wood $(-), b_{T O}{ }^{*}$ is yellow-blue values of the untreated teak wood ( - ).

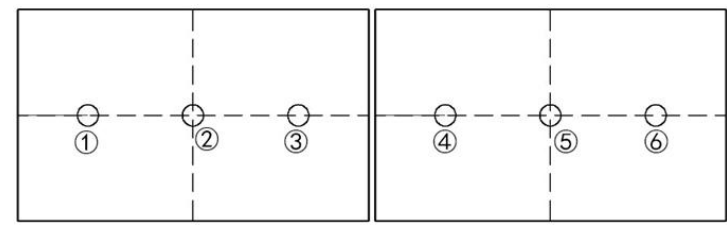

Fig. 1: Testing figure for colorimetric properties.

\section{Date analysis}

The date for $\Delta L^{*}, \Delta a^{*}, \Delta b^{*}$ and $\Delta E^{*}$ were examined for normality and homogeneity and found to be acceptable. Analysis of variance (ANOVA) was analyzed by $\mathrm{R}$ software (Version 3.6.1). The date for $\Delta L^{*}, \Delta a^{*}, \Delta b^{*}$ and $\Delta E^{*}$ were each subjected to analyses of variance $(\alpha=0.05)$ to determine the effects of heat treatment on the color properties. $P$ values were used to determine the significance of the ANOVA ( $P<0.05$ was considered to be significant).

\section{RESULTS AND DISCUSSION}

\section{Natural colorimetric parameters of control wood samples}

The natural colorimetric parameters $\left(L^{*}, a^{*}, b^{*}\right)$ of control wood samples were determined. Tab. 2 presents the initial colorimetric parameters for the untreated rubber wood and teak wood as control wood samples.

Tab. 2: The natural colorimetric parameters of control wood samples.

\begin{tabular}{|l|c|c|c|}
\hline \multicolumn{1}{|c|}{ Wood Species } & $\boldsymbol{L}^{*}$ & $\boldsymbol{a}^{*}$ & $\boldsymbol{b}^{*}$ \\
\hline Rubber wood & $80.94(0.31)$ & $4.37(0.23)$ & $21.69(2.56)$ \\
\hline Teak wood & $51.14(3.12)$ & $7.42(1.61)$ & $18.82(2.42)$ \\
\hline
\end{tabular}

Note: Standard deviations in parenthesis.

\section{Colorimetric parameters of heat-treated rubber wood}

The rubber wood was heat-treated under different treatment conditions according to the orthogonal test design $\left(\mathrm{L}_{9}\left(3^{4}\right)\right)$. The colorimetric parameters $\left(L^{*}, a^{*}, b^{*}, \Delta E^{*}\right)$ of the heat-treated rubber wood were measured (Tab. 3). 
Tab. 3: Colorimetric parameters of heat-treated rubber wood from the orthogonal test $L_{9}\left(3^{4}\right)$.

\begin{tabular}{|c|c|c|c|c|c|c|c|}
\hline No & $\boldsymbol{L}^{*}$ & $\boldsymbol{a}^{*}$ & $\boldsymbol{b}^{*}$ & $\Delta \boldsymbol{L}^{*}$ & $\Delta \boldsymbol{a}^{*}$ & $\Delta \boldsymbol{b}^{*}$ & $\Delta \boldsymbol{E}^{*}$ \\
\hline 1 & $64.22(0.30)$ & $9.75(0.17)$ & $25.300 .49)$ & $13.08(0.30)$ & $2.33(0.17)$ & $6.48(0.49)$ & $14.79(0.07)$ \\
\hline 2 & $63.00(2.01)$ & $10.02(0.23)$ & $24.99(0.93)$ & $11.86(2.01)$ & $2.60(0.23)$ & $6.17(0.93)$ & $13.63(2.12)$ \\
\hline 3 & $60.11(2.95)$ & $10.21(0.34)$ & $25.30(0.98)$ & $8.97(2.95)$ & $2.79(0.34)$ & $6.48(0.98)$ & $11.63(1.50)$ \\
\hline 4 & $54.42(0.65)$ & $10.37(0.17)$ & $23.11(0.18)$ & $3.28(0.65)$ & $2.95(0.17)$ & $4.29(0.18)$ & $6.16(0.51)$ \\
\hline 5 & $53.22(0.72)$ & $10.39(0.26$ & $22.11(0.40)$ & $2.08(0.72)$ & $2.97(0.25)$ & $3.29(0.40)$ & $4.93(0.44)$ \\
\hline 6 & $46.59(0.84)$ & $10.00(0.26)$ & $20.04(0.47)$ & $-4.55(0.84)$ & $2.58(0.26)$ & $1.22(0.47)$ & $5.42(0.55)$ \\
\hline 7 & $41.76(0.65)$ & $8.99(0.24)$ & $16.95(0.41)$ & $-9.38(0.65)$ & $1.57(0.24)$ & $-1.87(0.41)$ & $9.70(0.68)$ \\
\hline 8 & $37.70(1.41)$ & $8.40(0.23)$ & $14.46(0.96)$ & $-13.44(1.41)$ & $0.98(0.23)$ & $-4.36(0.96)$ & $14.17(1.62)$ \\
\hline 9 & $37.45(1.49)$ & $8.04(0.27)$ & $13.91(0.60)$ & $-13.69(1.49)$ & $0.62(0.27)$ & $-4.91(0.60)$ & $14.56(1.59)$ \\
\hline
\end{tabular}

Note: Standard deviations in parenthesis.

\section{Influence of process parameters on lightness $L^{*}$}

Lightness is a basic wood color parameter and in many applications is considered to be the most important parameter (Gašparík et al. 2019). Fig. 2 shows the changes in lightness of rubber wood with respect to treatment temperature, duration and heating rate. $L^{*}\left(\Delta L^{*}\right)$ decreased rapidly with temperature and duration increasing, whereas increased slowly with the increment of heating rate.
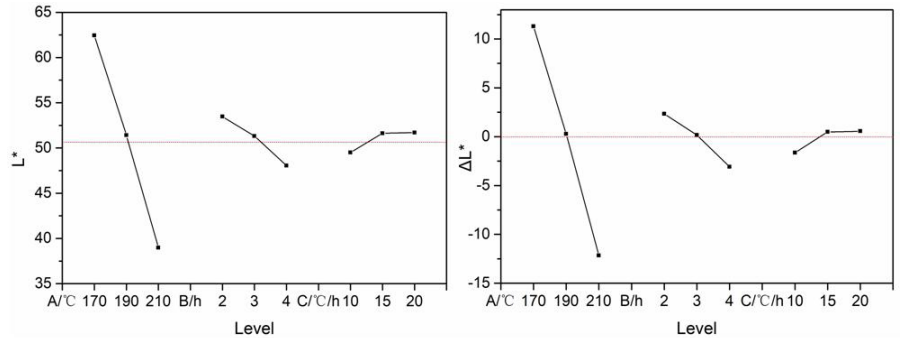

Fig. 2: Effect of process parameters on lightness of rubber wood.

Analysis of variance (ANOVA, Tab. 4) showed that the treatment temperature $(P<0.01)$ and duration $(P<0.05)$ had a significant effect on the lightness, and the heating rate had no significant effect.

Tab. 4: Results of analysis of variance of orthogonal test.

\begin{tabular}{|c|c|c|c|c|c|c|c|c|c|}
\hline Variable & $\begin{array}{c}\text { Variance } \\
\text { sources }\end{array}$ & F & $\mathbf{P}$ & Sig. & Variable & $\begin{array}{l}\text { Variance } \\
\text { sources }\end{array}$ & F & $\mathbf{P}$ & Sig. \\
\hline \multirow{3}{*}{$\Delta L^{*}$} & $\mathrm{~A}$ & 365.397 & 0.00273 & $* *$ & \multirow{3}{*}{$\Delta a^{*}$} & $\mathrm{~A}$ & 37.390 & 0.026 & $*$ \\
\hline & $\mathrm{B}$ & 19.699 & 0.0483 & $*$ & & $\mathrm{~B}$ & 0.860 & 0.538 & - \\
\hline & $\mathrm{C}$ & 4.111 & 0.1957 & - & & $\mathrm{C}$ & 2.630 & 0.275 & - \\
\hline \multirow{3}{*}{$\Delta b^{*}$} & $\mathrm{~A}$ & 391.324 & 0.00255 & $* *$ & \multirow{3}{*}{$\Delta E^{*}$} & A & 22.418 & 0.0427 & $*$ \\
\hline & B & 15.731 & 0.0598 & - & & B & 0.141 & 0.877 & - \\
\hline & $\mathrm{C}$ & 8.595 & 0.104 & - & & $\mathrm{C}$ & 2.840 & 0.260 & - \\
\hline
\end{tabular}

Different symbols $(* *, *)$ indicate significant difference at the $0.01,0.05$ level respectively according to ANOVA. 
The decline of value $L^{*}$ suggested that the surface color of rubber wood became darker and the color change became larger with the higher temperature and longer duration. The decrease of the $L^{*}$ value of rubber wood indicates that more visible light absorbing components is produced during the heat treatment process. A similar trend has been observed by other authors (Srinivas and Pandey 2012, Zhao et al. 2019). The minimum reduction $\Delta L^{*}$ was observed after 3-hour heat treatment at $190^{\circ} \mathrm{C}$ by $15^{\circ} \mathrm{C} \cdot \mathrm{h}^{-1}$ heating rate.

\section{Influence of process parameters on red-green index $a^{*}$ and yellow-blue index $b^{*}$}

From the experimental results in Tab. 3 , the effects of various process parameters on the red-green index $\left(a^{*}\right)$ and the yellow-blue index $\left(b^{*}\right)$ of the heat-treated rubber wood are shown in Fig. 3. The red-green index $a^{*}$ increased at the beginning of the treatment, and after reaching a maximum, $a^{*}$ decreased with higher temperature. The yellow-blue index $b^{*}$ decreased with different treatment temperature. $a^{*}$ and $b^{*}$ values decreased with longer heat-treated duration and increased with faster heating rate (Fig. 4). ANOVA (Tab. 4) showed that the treatment temperature had a significant effect on the $\mathrm{a}^{*}(P<0.05)$ and $\mathrm{b}^{*}(P<0.01)$. In this study, the redgreen index values of the heat-treated rubber wood increased, the wood color become reddish compared to the control wood. The minimum reduction $a^{*}$ and $b^{*}\left(\Delta a^{*}\right.$ and $\left.\Delta b^{*}\right)$ was observed after 4 -hour heat treatment by $10^{\circ} \mathrm{C} \cdot \mathrm{h}^{-1}$ heating rate.
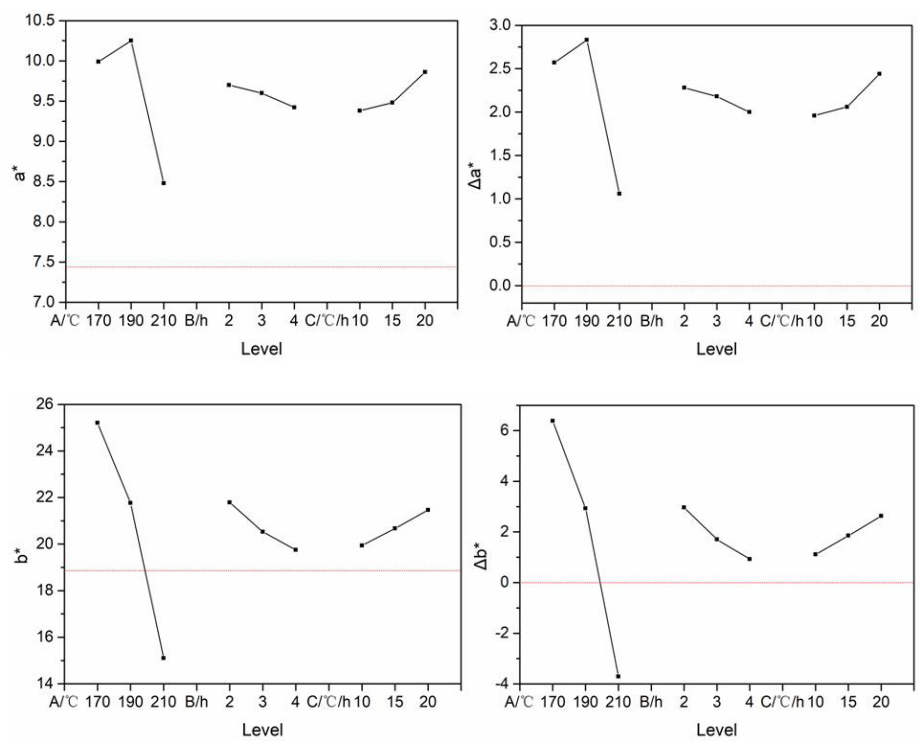

Fig. 3: Effect of process parameters on red-green index and yellow-blue index of rubber wood.

\section{Influence of process parameters on total color difference $\Delta E^{*}$}

Fig. 4 show the changes in total color difference $\left(\Delta E^{*}\right)$ of rubber wood with respect to treatment temperature, duration and heating rate compared to untreated rubber wood and teak wood. Compared with teak wood, values of $\Delta E^{*}$ decreased initially and later increased with higher temperature, whereas its values increased initially and later decreased with the increment of duration and heating rate. Heat treatment distinctly changed the original color of rubber wood, considering the fact that $\Delta E^{*}>3$ is a color difference that can be distinguished appreciably by 
a subjective observed. It is found that a pronounced color change with an increasing temperature from Fig. 4b. A more pronounced $\Delta E^{*}$ of 42.70 was found at $210^{\circ} \mathrm{C}$ compared with rubber wood. The $\Delta E^{*}$ was most affected by the heat treatment effect on the $L^{*}$ (Cuccui et al. 2017, Zanuttini et al. 2019). The color change values in the rubber wood found in this research corresponds with the results reported by Zhao et al. (2019). Minimum change in $\Delta E^{*}$ values for rubber wood was observed at temperature $190^{\circ} \mathrm{C}$, duration $2 \mathrm{~h}$ and $20^{\circ} \mathrm{C} \cdot \mathrm{h}^{-1}$, respectively.

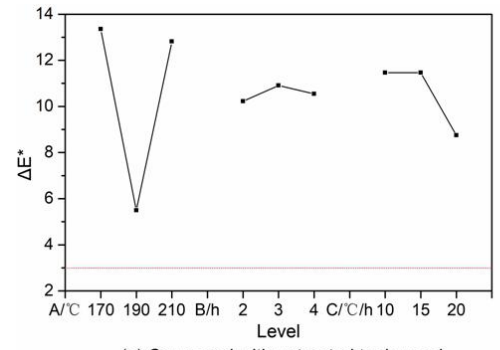

(a) Compared with untreated teak wood

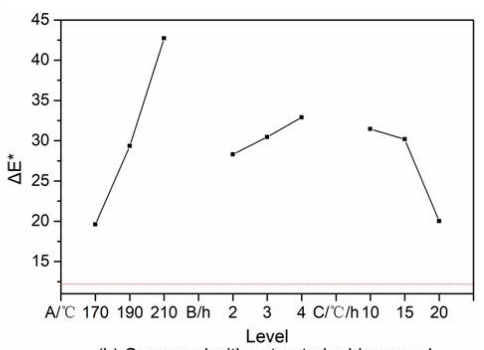

(b) Compared with untreated rubber wood

Fig. 4: Effect of process parameters on total color difference $\Delta E^{*}$ of rubber wood.

\section{Discussion}

The surface color of the rubber wood samples treated under different treatment conditions is shown in Fig. 5. When we focused on the colorimetric parameters, we found that the color changes were drastic after heat treatment at the temperature of 170 to $210^{\circ} \mathrm{C}$. From Fig. 5, it appears that the surface color of rubber wood exhibited a notable change, and the colors visible to the naked eye became darker. With the increase of the heat treatment temperature and the prolongation of the treatment duration, the color of the rubber wood gradually deepens, showing an elegant dark brown color, and the color of rubber wood treated at $190^{\circ} \mathrm{C}$ is close to the color of untreated teak wood.
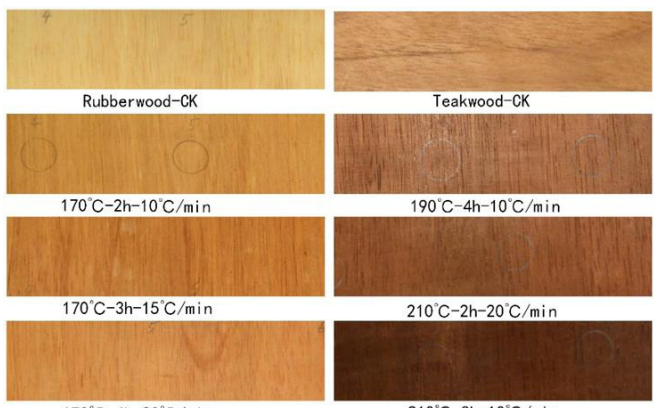

$210^{\circ} \mathrm{C}-2 \mathrm{~h}-20^{\circ} \mathrm{C} / \mathrm{min}$

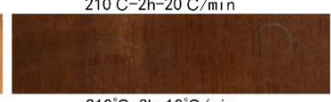

$170^{\circ} \mathrm{C}-4 \mathrm{~h}-20^{\circ} \mathrm{C} / \mathrm{min}$ $210^{\circ} \mathrm{C}-3 \mathrm{~h}-10^{\circ} \mathrm{C} / \mathrm{min}$

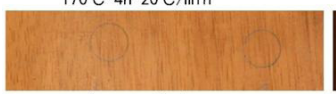

$190^{\circ} \mathrm{C}-2 \mathrm{~h}-15^{\circ} \mathrm{C} / \mathrm{min}$
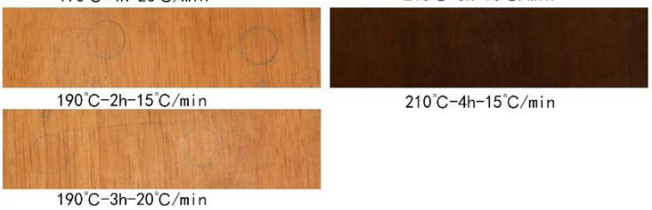

$210^{\circ} \mathrm{C}-4 \mathrm{~h}-15^{\circ} \mathrm{C} / \mathrm{min}$

$190^{\circ} \mathrm{C}-3 \mathrm{~h}-20^{\circ} \mathrm{C} / \mathrm{min}$

Fig. 5: Control wood samples (rubber wood and teak wood) and heat-treated rubber wood. 
The effect of heat-treatment conditions on color changes in wood has been studied by several authors (Bekhta and Niemz 2003, Srinivas and Pandey 2012, Mitani and Barboutis 2014, Barcík et al. 2015, Zanuncio et al. 2015). The factors causing color changes are manifold (Kúdela et al. 2017). The main factors affecting the thermal discoloration of wood include wood polysaccharide and lignin structure, $\mathrm{pH}$ value, heat treatment temperature and duration, extract content and structure (Varga and Van Der Zee 2008). Oxidation and self-condensation (acidic conditions) reactions that occur during heat treatment are also the main cause of darker coloring of wood. It is well known that change in the color of wood and treatment temperature are closely related. ANOVA also shows that the treatment temperature has a significant effect on the colorimetric parameters of the heat-treated rubber wood, and the heat-treated duration and heating rate has no effect, which is consistent with the results of the literatures (Wang 2017, Cao et al. 2018). From Tab. 3 and Fig. 5, it can be seen there is a clear correlation between the color data and the heat treatment intensity. Temperature, in fact, modifies lignin and extractives, degrades hemicelluloses and forms oxidation products, with higher temperatures resulting in darker colors (Welzbacher et al. 2007). Some researchers think that the color changes might be due to hydroxyl groups that were oxidized to carbonyl groups and carboxyl groups during heat treatment. If this is the case, then the wood color was darkened because the carbonyl groups belong to chromophric groups and the carboxyl groups to auxochromic groups (Funaoka et al. 1990, Cui and Matsumura 2019). However, it is necessary to qualitatively and quantitatively analyze the wood chemical composition in order to better understand the changes in wood color upon heating (Sun et al. 2019).

Comprehensive analysis of the effect of heat treatment process on the colorimetric parameters of rubber wood, in the scope of this experiment, the preferred process parameters are heat treatment temperature $190^{\circ} \mathrm{C}$, duration $4 \mathrm{~h}$, heating rate $10^{\circ} \mathrm{C} \cdot \mathrm{h}^{-1}$.

\section{CONCLUSIONS}

The effect of heat treatment process parameters on the surface color of rubber wood was analyzed. Within the scope of this experiment, the treatment temperature has a significant effect on the colorimetric parameters of the heat-treated rubber wood, the treatment duration and heating rate has no effect. Additionally, the order of these three factors which affect the surface color of rubber wood is the treatment temperature > treatment duration > heating rate. Within the experimental range, as the heat treatment temperature and duration increasing, the color of the rubber wood gradually deepens. In order to achieve a color like the teak wood, the preferred process conditions are heat treatment temperature $190^{\circ} \mathrm{C}$, duration $4 \mathrm{~h}$, heating rate $10^{\circ} \mathrm{C} \cdot \mathrm{h}^{-1}$.

\section{ACKNOWLEDGMENTS}

The authors are grateful for the support of the Central Public-interest Scientific Institution Basal Research Fund for Chinese Academy of Tropical Agricultural Sciences (China), Grant No. 1630022018020 and the Opening Project Fund of Key Laboratory of Biology and Genetic Resources of Rubber Tree, Ministry of Agriculture and Rural Affairs, P. R. China / State Key Laboratory Breeding Base of Cultivation \& Physiology for Tropical Crops / Danzhou Investigation \& Experiment Station of Tropical Crops, Ministry of Agriculture and Rural Affairs (China), Grant No. RRI-KLOF201901 and RRI-KLOF201705. 


\section{REFERENCES}

1. Barcík, Š., Gašparík, M., Razumov, E.Y., 2015: Effect of thermal modification on the colour changes of oak wood. Wood Research 60(3): 385-396.

2. Bekhta, P., Niemz, P., 2003: Effect of high temperature on the change in color, dimensional stability and mechanical properties of spruce wood. Holzforschung 57(5): 539-546.

3. Cai, S., Zhang, N., Li, K., Li, Y., Wang, X., Cai, S., 2019: Effect of pressurized hot water treatment on the mechanical properties, surface color, chemical composition and crystallinity of pine wood. Wood Research 64(3): 389-400.

4. Cao, Y., Li, X., Wang, S., Li, Y., Li, W., 2018: Effects of thermal treatment on color in eucalyptus urophylla wood. Forestry and Environmental Science 34(1): 18-20 (in Chinese).

5. Cuccui, I., Negro, F., Zanuttini, R., Espinoza, M., Allegretti, O., 2017: Thermo-vacuum modification of teak wood from fast-growth plantation. Bioresources 12(1): 1903-1915.

6. Cui, X., Matsumura, J., 2019: Wood surface changes of heat-treated Cunninghamia lanceolate following natural weathering. Forests 10(9): 791.

7. Dzurenda, L., 2018: The shades of color of Quercus robur L. wood obtained through the processes of thermal treatment with saturated water vapor. Bioresources 13(1): 1525-1533.

8. Esteves, B., Ayata, U., Gurleyen, L., 2019: Effect of heat treatment on the colour and glossiness of black locust, wild pear, linden, alder and willow wood. Drewno 62(203): 39-52.

9. Funaoka, M., Kako, T., Abe, I., 1990: Condensation of lignin during heating of wood. Wood Science and Technology 24(3): 277-288.

10. Gašparík, M., Gaff, M., Kačík, F., Sikora, A., 2019: Color and chemical changes in teak (Tectona grandis L. F.) and meranti (Shorea spp.) wood after thermal treatment. Bioresources 14(2): 2667-2683.

11. González-Peña, M.M., Hale, M.D.C., 2009: Colour in thermally modified wood of beech, Norway spruce and scots pine. Part 2: property predictions from colour changes. Holzforschung 63(4): 394-401.

12. Griebeler, C., Tondi, G., Schnabel, T., Iglesias, C., Ruiz, S., 2018b: Reduction of the surface colour variability of thermally modified Eucalyptus globulus wood by colour pre-grading and homogeneity thermal treatment. European Journal of Wood and Wood Products 76(5): 1495-1504.

13. Griebeler, C.G.D.O., Matos, J.L.M.D., Muniz, G.I.B.D., Nisgoski, S., Batista, D.C., Rodríguez, C.I., 2018a: Colour responses of Eucalyptus grandis wood to the Brazilian process of thermal modification. Maderas. Ciencia y tecnología 20(4): 661-670.

14. Hrčková, M., Koleda, P., Koleda, P., Barcík, Š., Štefková, J., 2018: Color change of selected wood species affected by thermal treatment and sanding. Bioresources 13(4): 8956-8975.

15. Jankowska, A., Stepniewski, S., 2010: Research on colour change of thermal modified birch wood caused by UV and accelerated ageing. Annals of Warsaw University of Life Sciences - SGGW. Forestry and Wood Technology 71: 280-284.

16. Jiang, H., Fu, F., 2017: Colorimetric and thermochromic properties of reversible thermochromic wood. Wood Research 62(1): 57-66.

17. Kúdela, J., Kubovský, I., Andrejko, M., 2018: Impact of different radiation forms on beech wood discolouration. Wood Research 63(6): 923-934.

18. Kúdela, J., Rešetka, M., Rademacher, P., Dejmal, A., 2017: Influence of pressing parameters on surface properties of compressed beech wood. Wood Research 62(6): 939-950.

19. Lin, L., Yang, Y., Qiu, J., Luo, B., Qin, L., 2017: Effects of thermo-vacuum treatment on the anatomical structures of szemao pine wood and alder birch wood. Wood Research 62(5): 673-682. 
20. Mitani, A. and Barboutis, I., 2014: Changes caused by heat treatment in color and dimensional stability of beech (Fagus sylvatica L.) Wood. Drvna Industrija 65(3): 225-232.

21. Nasir, V., Nourian, S., Avramidis, S., Cool, J. 2019: Prediction of physical and mechanical properties of thermally modified wood based on color change evaluated by means of "group method of data handling" (GMDH) neural network. Holzforschung 73(4): 381-392.

22. Salca, E., Kobori, H., Inagaki, T., Kojima, Y., Suzuki, S. 2016: Effect of heat treatment on colour changes of black alder and beech veneers. Journal of Wood Science 62(4): 297-304.

23. Shi, J., Lu, Y., Zhang, Y., Cai, L., Shi, S.Q. 2018: Effect of thermal treatment with water, $\mathrm{H} 2 \mathrm{SO} 4$ and $\mathrm{NAOH}$ aqueous solution on color, cell wall and chemical structure of poplar wood. Scientific Reports 8(1): 17735.

24. Sikora, A., Kačík, F., Gaff, M., Vondrová, V., Bubeníková, T., Kubovský, I., 2018: Impact of thermal modification on color and chemical changes of spruce and oak wood. Journal of Wood Science 64(4): 406-416.

25. Srinivas, K., Pandey, K.K., 2012: Effect of heat treatment on color changes, dimensional stability, and mechanical properties of wood. Journal of Wood Chemistry and Technology 32(4): 304-316.

26. Sun, B., Wang, Z., Liu, J., 2019: Study on color and surface chemical properties of Eucalyptus pellita wood subjected to thermo-vacuum treatment. Wood Research 64(1): 1-11.

27. Van Nguyen, T.H., Nguyen, T.T., Ji, X., Guo, M. 2018: Predicting color change in wood during heat treatment using an artificial neural network model. Bioresources 13(3): 6250-6264.

28. Varga, D., Van der Zee, M.E., 2008: Influence of steaming on selected wood properties of four hardwood species. Holz als Roh- und Werkstoff 66(1): 11-18.

29. Wang, Z., 2017: Study on properties and mechanism of larch wood modified by vacuum heat treatment. Doctor's thesis. Chinese Academy of Forestry, Beijing (in Chinese), Pp 37-46.

30. Welzbacher, C.R., Brischke, C., Rapp, A.O., 2007: Influence of treatment temperature and duration on selected biological, mechanical, physical and optical properties of thermally modified timber. Wood Material Science \& Engineering 2(2): 66-76.

31. Wongprot, T., Matan, N., Matan, N., Wanchart, P., Kyokong, B., 2013: Response surface modeling of hydrothermal treatment conditions on color changes, strength, and durability properties of rubberwood. Bioresources 8(1): 302-312.

32. Yan, L., Morrell, J.J.: 2019: Kinetic color analysis for assessing the effects of borate and glycerol on thermal modification of wood. Wood Science and Technology 53(1): 263-274.

33. Zanuncio, A.J.V., Carvalho, A.G., Teixeira De Souza, M., Marangon Jardim, C., de Cassia Oliveira Carneiro, A., Luiz Colodette, J., 2015: Effect of extractives on wood color of heat treated Pinus radiata and Eucalyptus pellita. Maderas. Ciencia y tecnología 17(4): 857-864.

34. Zanuttini, R., Castro, G., Cremonini, C., Negro, F., Palanti, S., 2020: Thermo-vacuum treatment of poplar (Populus spp.) plywood. Holzforschung 74(1): 60-67.

35. Zhao, X., Tu, D., Chen, C., Zhou, Q. 2019: Prediction of the mechanical properties of thermally-modified rubber wood on the basic of its surface characteristic. Wood Research 64(1): 25-34. 
Huichuan Jiang*, Quanji Lu, Guanjun Li, Min Li, Jianing Li Rubber Research Institute

Chinese Academy of Tropical Agricultural Sciences

Key Laboratory of Biology and Genetic Resources of Rubber Tree

Ministry of Agriculture and Rural Affairs, P. R. China

Haikou 57IIOI

China

*Corresponding author: jianghc@126.com 
